\title{
Management of sorghum anthracnose through diversification of genetic resistance in host population
}

\author{
Breno O. Souza ${ }^{1}$, Carlos R. Casela ${ }^{2}$, José A. Nunes ${ }^{3}$ \& Hilário A. Castro ${ }^{1}$ \\ ${ }^{1}$ Departamento de Fitopatologia, Universidade Federal de Lavras, Cx. Postal 3037, 37000-200, Lavras, MG, Brazil; ${ }^{2}$ Embrapa \\ Milho e Sorgo, Cx. Postal 151, 35701-970, Sete Lagoas, MG, Brazil; ${ }^{3}$ Departamento de Biologia, Universidade Federal de \\ Lavras, Cx. Postal 3037, 37000-200, Lavras, MG, Brazil
}

Author for correspondence: Breno O. Souza, e-mail: souzabio@yahoo.com.br

\begin{abstract}
The aims of the present study were to assess the efficiency of hybrid sorghum mixtures for the management of anthracnose and analyze the virulence diversity and structure in the pathogen populations developed in response to these mixtures. Proportions of $25 \%$, $50 \%$ and $75 \%$ of the susceptible BRS304 hybrid in relation to the resistant IG150 hybrid were evaluated. Six weekly evaluations of severity were performed. The data were transformed into area under disease progress curve (AUDPC). The isolates of Colletotrichum sublineolum were sampled from hybrid mixtures cultivated in Sete Lagoas and Indianópolis (Brazil) as well as sorghum fields in Rio Verde and Paraúna (Brazil). The increase in the proportion of the resistant hybrid in the mixtures led to a reduction in anthracnose severity. The most effective proportions were those with $25 \%$ and $50 \%$ of the susceptible variety blended with the resistant variety. Complex breeds of $C$. sublineolum predominated in the populations and a reduction in phenotype diversity was observed. This reduction in diversity was attributed to deviations in the degree of polymorphism in relation to virulence. However, the increase in complex breeds did not imply lesser efficiency on the part of the resistant hybrid in conferring protection to the susceptible hybrid.
\end{abstract}

Key words: Colletotrichum sublineolum, Sorghum bicolor, cultivars mixtures, virulence diversity, virulence structure.

\section{INTRODUCTION}

Anthracnose is caused by Colletotrichum sublineolum and is the most severe disease affecting sorghum crops in Brazil. Under favorable conditions, the disease occurs in all crop regions of the country and can cause huge losses among susceptible varieties. The use of resistant varieties is the most efficient and economical strategy for controlling this pathogen. However, the pathogen exhibits a variability that allows its rapid adaptation to the genetic resistance found in commercial varieties of sorghum (Costa et al., 2003; Silva et al., 2008).

Diversification of the host population is one of the alternatives for hindering the rapid adaptation of pathogens with a high degree of variability for overcoming genetic resistance. This diversification can be performed through the use of multilines or mixtures of varieties in the form of non-isogenic lines (Wolfe, 1985; Lannou \& Mundt, 1996). Multilines and mixtures are based on the occurrence of the confrontation of the pathogen with a broad diversity of resistance genes in the host (Parlevliet, 1993; Casela et al., 2001), leading to a reduction in the severity of the disease and a broadening of variability in the pathogen. Guimarães et al. (1998) and Costa et al. (2005) analyzed this process in the Sorghum bicolor/Colletotrichum sublineolum pathosystem and assessed the efficiency of sorghum mixtures in controlling anthracnose in Brazil. However, an increase in the frequency of super breeds or complex breeds was observed, along with a reduction in virulence diversity in sorghum mixtures in comparison to the pure stands (Valério et al., 2004). Super-breeds or complex breeds are those that are virulent to all or nearly all the component genotypes in a mixture of cultivated plants. The emergence of super breeds in plant crops may lead to a reduction in the useful life of mixtures in the field (Lannou \& Mundt, 1996). One of the possible benefits of the use of sorghum mixtures is to extend the useful life of the plants in the field. Thus, a variety with considerable agronomic value that had its resistance overcome due to changes in the pathogen population could continue to be viable as a crop.

The aims of the present study were to assess the possibility of a resistant sorghum hybrid conferring protection to a susceptible variety through mixtures and analyze the virulence diversity and structure in the $C$. sublineolum populations developed in response to these mixtures.

\section{MATERIALS AND METHODS}

The experiments were conducted at Embrapa Milho e Sorgo in Sete Lagoas and the experimental areas of Dow Agrosciences in Indianópolis (both in the state of Minas Gerais, Brazil). Four sorghum crops were cultivated designated Crops I, II, III and IV. The summer crops (I and 
II; grown in Sete Lagoas and Indianópolis, respectively) were assessed under conditions of a natural epidemic. The winter crops (III and IV; grown in Sete Lagoas) were inoculated artificially due to the unfavorable environmental conditions for the occurrence of the disease.

The experimental plots were made up of two rows with a length of $8 \mathrm{~m}$, separated by a row of corn plants. The spacing between rows was $0.9 \mathrm{~m}$. A border plant of the susceptible BR009 variety was placed at one of the ends of each experimental plot. This border plant served as an indicator of the natural inoculate potential in Crops I and II as well as to determine the efficiency of the artificial inoculations in Crops III and IV. The border plant also served as an indicator of the response of a highly susceptible, genetically uniform host population to the pathogen.

The artificial inoculum in Crops III and IV was a mixture of four isolates $\left(1.2 \times 10^{6}\right.$ conidia $/ \mathrm{mL}$ in $10 \mathrm{~L}$ of distilled, sterilized water). Each isolate expressed a characteristic virulence pattern: Isolate 1 , virulent to the BRS304 and IG150 varieties; Isolate 2, virulent to BRS304 and avirulent to IG150; Isolate 3, virulent to IG150 and avirulent to BRS304; Isolate 4, avirulent to IG150 and BRS304. Inoculation was performed on the susceptible border plant by means of aspersion. This inoculation was performed in order to increase the inoculate pressure on the crops and increase the intensity of the disease in the field.

Six treatments were analyzed, involving proportions of mixtures and pure stands of the BRS304 (Embrapa Milho e Sorgo) and IG150 (Dow Agrosciences) hybrids: 1 - IG150 $(100 \%) ; 2$ - IG150 (25\%) + BRS304 (75\%); 3 - IG150 $(50 \%)+$ BRS304 (50\%); $4-\mathrm{IG} 150(75 \%)+\mathrm{BRS} 304(25 \%) ;$ 5 - BRS304 (100\%); and 6 - BR009 (100\%; susceptible control. The experiment was randomized complete block design (RCBD) with three replications. The BRS304 hybrid is widely used by sorghum growers in Brazil. Its resistance to anthracnose has been overcome by the emergence of virulent breeds of $C$. sublineolum. IG150 is considered resistant to the disease and the BR009 lineage is considered universally susceptible.

Six plants per row were randomly marked in each experimental plot for the evaluation of anthracnose severity. Six evaluations were performed on these plants with regard to the leaf area affected by the disease beginning 57 days after the sowing of Crops I and II and 27 days after the inoculation of Crops III and IV. These evaluations were performed with weekly intervals and based on a modified version of the scoring scale established by Sharma (1983), with scores of 1 to 13, for which 1 denotes the absence of anthracnose and 13 denotes $100 \%$ of the leaf area affected by the disease. Disease severity data were converted to AUDPC following the method proposed by Shanner \& Finney (1977). Moreover, the productivity of each treatment was determined through the transformation of the weight of the grains in grams per plot $(\mathrm{g} / \mathrm{plot})$ to kilograms per $(\mathrm{kg} / \mathrm{ha})$.

Joint analysis of variance was performed of the AUDPC and treatment production data, based on Ramalho et al. (2005). The field results were analyzed with conventional analysis of variance, correlation and regression, using the Statistical Analysis System (SAS). Comparisons between mean values were performed using the Scott-Knott test at $5 \%$ probability. Pearson correlation (r) values were calculated for the diversity indexes and between these indexes and complexity, followed by the Student's t-test at $5 \%$ and $1 \%$ probability.

\section{Colletotrichum sublineolum population structure and diversity}

The C. sublineolum population structure was analyzed through a differential series of hybrids of the mixtures evaluated. BR310 and 992045 (Embrapa Milho e Sorgo) and DAS740 (Dow Agrosciences) were included in the differential series. The treatments were distributed in an entirely random design. The isolates were distributed among the plots and the hybrids were distributed in subplots with three replicates. One pot with three to four plants was considered one replicate.

One hundred fifty-seven monosporic isolates were tested in a greenhouse for the assessment of the diversity of the pathogen developed in response to the different treatments. One hundred nine of these isolates were from populations developed in response to the hybrid mixtures analyzed in summer - 60 from Sete Lagoas and 49 from Indianópolis. Comparisons were performed among the virulence structures of the pathogen populations sampled from the mixtures and those developed under commercial sorghum crop conditions. For such, 48 isolates from sorghum fields located in the municipalities of Rio Verde and Paraúna (State of Goiás, Brazil) were included in the virulence analysis.

The isolates were all proportions of mixtures. They were obtained from leaves with symptoms of anthracnose. Leaf fragments with signs and symptoms of the pathogen were disinfected in a $1 \%$ sodium hypochlorite solution for two minutes. These fragments were plated in an oatmeal agar medium. The plates were incubated under a 12-hour photoperiod at a temperature of approximately $27^{\circ} \mathrm{C}$ for seven to eight days. For the induction of abundant sporulation, scraping of the developed surface mycelium was performed three days after isolation. Three days after scraping, fragments from the culture medium containing the developed fungus were collected and transferred to test tubes with $9 \mathrm{~mL}$ of distilled, sterilized water. Four serial dilutions were performed with the transference of 1 $\mathrm{mL}$ of the spore suspension from the previous tube to the subsequent tube with $9 \mathrm{~mL}$ of distilled, sterilized water. Thus, the concentration of spores was approximately 50 to 100 conidia $/ \mathrm{mL}$ in the fourth tube. One $\mathrm{mL}$ of the final spore suspension (fourth tube) was then distributed between two Petri dishes containing 2\% agar-water. These dishes were incubated at $27^{\circ} \mathrm{C}$ for 12 hours for the induction of conidium germination. Monosporic cultures were obtained through the sewing of a single conidium located in a circular fragment 
of agar-water. Each fragment was transferred to test tubes containing oatmeal agar medium and incubated under a 12hour photoperiod for seven days. Finally, mineral oil was added to the tubes with the grown monosporic isolates until use.

The monosporic isolates were transferred from the cultures in the tubes containing mineral oil to Petri dishes containing oatmeal agar medium and kept under a 12-hour photoperiod for five to six days. After three days, scraping was performed of the surface mycelium in order to stimulate sporulation. Five days after the scraping, the spores produced were transferred to two Petri dishes containing oatmeal agar medium. Three days after the transference of the spores, scraping was performed on the mycelium grown in the Petri dishes. Five days later, the dishes were inundated with distilled, sterilized water, thereby releasing the conidia. Counts of the inoculate suspension were carried out in a Neubauer chamber with adjustment to a concentration of $1.2 \times 10^{6}$ conidia $/ \mathrm{mL}$.

The sorghum hybrids were inoculated in a greenhouse 28 days after planting. The plants were then incubated in a wet chamber for 18 to 20 hours at a temperature of $27 \pm 5^{\circ} \mathrm{C}$. Ten days after inoculation, the plants were evaluated with regard to the signs of the pathogen and symptoms of anthracnose using a scoring scale based on the type of infection ranging from 1 to 5 (Cardwel et al., 1989). Two reaction classes were considered: $\mathrm{R}=$ presence of hypersensitivity lesions; and $\mathrm{S}=$ sporulating lesions characterized by the presence of acervuli of the pathogen. These two types of reaction designated the breeds of the pathogen based on the binary system employed by Habgood (1970).

The phenotype diversity of each pathogen population was estimated using the Shannon, Simpson and Gleason indexes (Groth \& Roelfs, 1987a). The complexity of the breeds was estimated based on Andrivon \& VallaviellePoppe (1995). The influence of virulence frequency and association of virulence factors in $C$. sublineolum was determined. For such, the efficiency of the Shannon index in detecting the diversity of the populations was determined. Thus, the effects of deviations in the degree of polymorphism $(\mathrm{Pd})$ were determined in relation to the ideal frequency of 0.5 of virulence to a given genotype in the differential series and the effects of virulence factors in the pathogen $(\mathrm{Pa})$ on the phenotype diversity of the populations analyzed were determined (Groth \& Roelfs, 1987b). The isolates were also analyzed with regard to distribution, frequency and virulence in sites with mixtures and pure stands.

\section{RESULTS}

The severity of the disease on the blended BRS304 hybrid was lesser than that on its pure stands and the BR009 control. The increase in the proportion of the resistant hybrid in the mixtures resulted in a reduction in anthracnose severity in both seasons. Greater severity of the disease was found in the crops cultivated in summer than those cultivated in winter. In all crops, mixtures containing $25 \%$ and $50 \%$ of the susceptible BRS304 variety were more efficient at reducing the disease-progress curve (Table 1). In both seasons, the most efficient treatments regarding the reduction of the disease were not the most productive. However, all treatments produced better than the BR009, considered susceptible universal (Table 1).

The mixture containing $75 \%$ of the resistant variety reduced the severity of the disease in the crops by as much as $63.81 \%$. Treatment $3(50 \%$ BRS304 + 50\% IG150) was the most efficient in Crops II (Indianópolis) and III (Sete Lagoas) (Table 2).

\section{Colletotrichum sublineolum population structure and diversity}

In the populations of $C$. sublineolum sampled, 20 breeds were identified among the 157 monosporic isolates inoculated in the five differentiating sorghum treatments. Twelve of which were detected in Sete Lagoas; 18 were detected in Indianópolis; and 12 were detected in Rio Verde and Paraúna. At all sampling sites, Breed 31 was the most frequent, occurring with frequencies of $63.3 \%, 28.6 \%$ and $33.3 \%$ in Sete Lagoas, Indianópolis and Rio Verde/Paraúna, respectively. Breeds 25 and 27 also exhibited high frequency values in all sites. Breeds 14 and 24 were only detected in Sete Lagoas and Breeds 4, 17 and 26 were only detected in Indianópolis. Breeds 31 (33.3\%) and 27 (22.9\%) were

TABLE 1 - Yield and area under disease progress curve of anthracnose in two sorghum hybrids blended in different proportions in summer and winter crops

\begin{tabular}{|c|c|c|c|c|}
\hline \multirow[t]{3}{*}{ Treatment } & \multicolumn{4}{|c|}{ Season } \\
\hline & \multicolumn{2}{|c|}{ Summer $^{1}$} & \multicolumn{2}{|c|}{ Winter $^{2}$} \\
\hline & Yield $^{3}$ & AUDPC $^{4}$ & Yield $^{3}$ & AUDPC $^{4}$ \\
\hline IG150 (100\%) & $2454.7 \mathrm{a}$ & $247.3 \mathrm{a}$ & $1345.9 \mathrm{a}$ & $751.3 \mathrm{a}$ \\
\hline BRS304 (25\%)+ IG150 (75\%) & $1848.3 \mathrm{a}$ & $353.3 \mathrm{a}$ & $1607.8 \mathrm{a}$ & $900.0 \mathrm{a}$ \\
\hline BRS304 (50\%) + IG150 (50\%) & $2061.4 \mathrm{a}$ & $584.3 \mathrm{~b}$ & $1534.1 \mathrm{a}$ & $923.7 \mathrm{a}$ \\
\hline BRS304 (75\%) + IG150 (25\%) & $2141.0 \mathrm{a}$ & $877.2 \mathrm{~b}$ & $1580.4 \mathrm{a}$ & $941.3 \mathrm{a}$ \\
\hline BRS304 $(100 \%)$ & $2554.1 \mathrm{a}$ & $1166.8 \mathrm{c}$ & $1729.8 \mathrm{a}$ & $1309.7 \mathrm{~b}$ \\
\hline BR009 Control & $876.2 \mathrm{~b}$ & $1776.0 \mathrm{~d}$ & $1282.5 \mathrm{a}$ & $1507.0 \mathrm{~b}$ \\
\hline
\end{tabular}

${ }^{1}$ Means of Crops I and II in Sete Lagoas and Indianópolis, respectively; ${ }^{2}$ means of Crops III and IV in Sete Lagoas; ${ }^{3}$ yield in kg/ha; ${ }^{4}$ area under disease-progress curve; means of treatments followed by same letter do not differ significantly (Scott-Knott test, $5 \%$ probability). 
the most frequent in the fields in Rio Verde and Paraúna. However, breeds with a small virulence spectrum, such as Breeds $2(8.3 \%)$ and $9(8.3 \%)$, were the third most frequent at these sites (Table 3 ).
Complex breeds with two, three and four numbers of virulence predominated in the mixtures in Sete Lagoas and Indianópolis. Breeds with a high number of virulence were also observed in the fields in Rio Verde and Paraúna, but

TABLE 2 - Anthracnose severity on sorghum hybrid blends in relation to susceptible materials

\begin{tabular}{|c|c|c|c|}
\hline Season & Crop & Treatment & Severity $^{4}$ \\
\hline \multirow{2}{*}{ Summer } & $\mathrm{I}^{1}$ & $\begin{array}{c}100 \% \text { IG } 150 \\
75 \%+25 \% \\
50 \%+50 \% \\
25 \%+75 \% \\
100 \% \text { BRS304 } \\
\text { BR009 }\end{array}$ & $\begin{array}{r}3.6 \mathrm{a} \\
7.3 \mathrm{a} \\
14.1 \mathrm{a} \\
14.1 \mathrm{a} \\
20.4 \mathrm{a} \\
40.3 \mathrm{~b}\end{array}$ \\
\hline & $\mathrm{II}^{2}$ & $\begin{array}{c}100 \% \text { IG } 150 \\
75 \%+25 \% \\
50 \%+50 \% \\
25 \%+75 \% \\
100 \% \text { BRS } 304 \\
\text { BR009 }\end{array}$ & $\begin{array}{l}11.5 \mathrm{a} \\
14.3 \mathrm{a} \\
17.1 \mathrm{a} \\
32.4 \mathrm{~b} \\
40.9 \mathrm{~b} \\
47.8 \mathrm{~b} \\
\end{array}$ \\
\hline Winter & $\mathrm{III} / \mathrm{IV}^{3}$ & $\begin{array}{c}100 \% \text { IG } 150 \\
75 \%+25 \% \\
50 \%+50 \\
25 \%+75 \% \\
100 \% \text { BRS304 } \\
\text { BR009 }\end{array}$ & $\begin{array}{r}9.9 \mathrm{a} \\
15.1 \mathrm{~b} \\
23.6 \mathrm{c} \\
34.4 \mathrm{~d} \\
43.8 \mathrm{e} \\
57.8 \mathrm{f}\end{array}$ \\
\hline
\end{tabular}

${ }^{1}$ Summer crop in Sete Lagoas; ${ }^{2}$ summer crop in Indianópolis; ${ }^{3}$ winter crop in Sete Lagoas; ${ }^{4}$ disease severity in percentage $(\%)$. Means of treatments followed by same letter do not differ significantly (Scott-Knott test, $5 \%$ probability).

TABLE 3 - Virulence phenotypes of Colletotrichum sublineolum identified in blends and sorghum fields

\begin{tabular}{|c|c|c|c|c|c|c|c|c|}
\hline \multirow[t]{2}{*}{ Breed } & \multicolumn{2}{|c|}{ Sete Lagoas } & \multicolumn{2}{|c|}{ Indianópolis } & \multicolumn{2}{|c|}{ Rio Verde and Paraúna } & \multirow[t]{2}{*}{ Total $^{2}$} & \multirow[t]{2}{*}{$\left(\mathbf{F r}^{2}\right)^{3}$} \\
\hline & $\begin{array}{l}\text { Number of } \\
\text { isolates }\end{array}$ & $\left(\mathrm{Fr}^{2}\right)^{1}$ & $\begin{array}{l}\text { Number of } \\
\text { isolates }\end{array}$ & $\left(\mathrm{Fr}^{2}\right)^{1}$ & $\begin{array}{l}\text { Number of } \\
\text { isolates }\end{array}$ & $\left(\mathrm{Fr}^{2}\right)^{1}$ & & \\
\hline 1 & & & 3 & 0.061 & 2 & 0.042 & 5 & 0.032 \\
\hline 2 & & & 1 & 0.020 & 4 & 0.083 & 5 & 0.032 \\
\hline 3 & & & 2 & 0.041 & 1 & 0.021 & 3 & 0.019 \\
\hline 4 & & & 1 & 0.020 & & & 1 & 0.006 \\
\hline 5 & & & 1 & 0.020 & & & 1 & 0.006 \\
\hline 7 & 1 & 0.017 & 2 & 0.041 & & & 3 & 0.019 \\
\hline 9 & 1 & 0.017 & 1 & 0.020 & 4 & 0.083 & 6 & 0.038 \\
\hline 11 & 1 & 0.017 & 2 & 0.041 & 2 & 0.042 & 5 & 0.032 \\
\hline 14 & 1 & 0.017 & & & & & 1 & 0.006 \\
\hline 15 & 1 & 0.017 & 1 & 0.020 & 1 & 0.021 & 3 & 0.019 \\
\hline 17 & & & 1 & 0.020 & & & 1 & 0.006 \\
\hline 18 & 1 & 0.017 & 2 & 0.041 & 2 & 0.042 & 5 & 0.032 \\
\hline 19 & 3 & 0.050 & 3 & 0.061 & 1 & 0.021 & 7 & 0.045 \\
\hline 23 & & & 1 & 0.020 & 1 & 0.021 & 2 & 0.013 \\
\hline 24 & 1 & 0.017 & & & & & 1 & 0.006 \\
\hline 25 & 4 & 0.067 & 4 & 0.082 & 3 & 0.063 & 11 & 0.070 \\
\hline 26 & & & 1 & 0.020 & & & 1 & 0.006 \\
\hline 27 & 7 & 0.117 & 8 & 0.163 & 11 & 0.229 & 26 & 0.166 \\
\hline 29 & 1 & 0.017 & 1 & 0.020 & & & 2 & 0.013 \\
\hline 31 & 38 & 0.633 & 14 & 0.286 & 16 & 0.333 & 68 & 0.433 \\
\hline Total & 60 & 1 & 49 & 1 & 48 & 1 & 157 & 1 \\
\hline
\end{tabular}

${ }^{1}$ Frequency of breed at site; ${ }^{2}$ total isolates of breed; ${ }^{3}$ total frequency of breed. 
breeds with one and two numbers of virulence were found in expressive number at these sites (Figure 1).

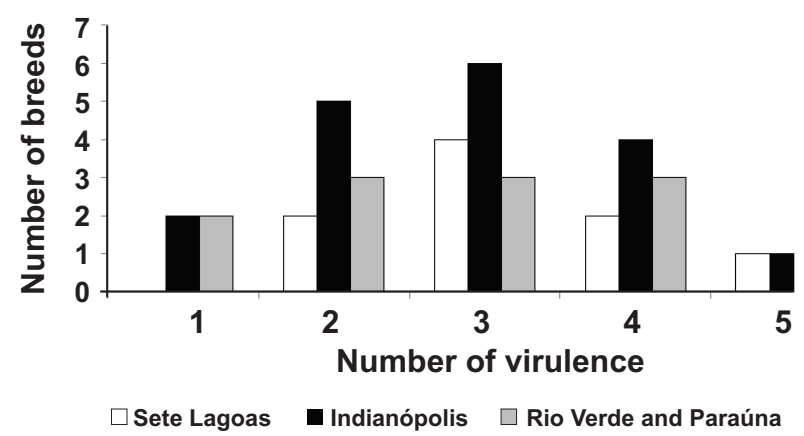

FIGURE 1 - Frequency distribution of virulence groups of Colletotrichum sublineolum on five sorghum hybrids in four regions of Brazil.

Based on the results of the Shannon and Gleason indexes, the greatest phenotype diversity occurred in Indianópolis and the least diversity occurred in Sete Lagoas. In the population sampled from Rio Verde and Paraúna, few phenotypes were identified. These sites achieved the second highest values on the Shannon and Gleason indexes and the phenotypes exhibited more homogeneous distribution (Table 4).

The complexity of the breeds in the population in Indianópolis was lesser than that observed for the population in Sete Lagoas. The breeds sampled from the Indianópolis mixtures achieved a complexity value close to the one found in the population collected from the sorghum fields (Table 5). Based on the Shannon index, greater reductions in the estimated of population diversity were determined by the Pd in Sete Lagoas, Rio Verde and Paraúna. In Indianópolis, these reductions were due to $\mathrm{Pa}$ although the Pd was also high (Table 5).

No correlations (r) were found between the diversity indexes for the populations of $C$. sublineolum sampled (Table 6). However, a significant positive correlation was found between the Simpson diversity index and breed complexity.

\section{DISCUSSION}

The use of the resistant IG150 hybrid at greater proportions in the mixtures reduced the severity of anthracnose. Similarly, Sifuentes-Barrera \& Frederiksen (1994) reported a reduction in the severity of leaf burn caused by Exserohilum turcicum with the use of mixtures of experimental hybrids at different proportions.

The resistant genotype in mixtures may act as a physical barrier to the dispersion of the pathogen, which is equal to reducing the action of the allo-infection in sensu Robinson (1976) mixtures. Moreover, the number of susceptible genotype units per cultivation area, the way in which these units are arranged and distributed and the degree of pathogen-host specificity exert an influence over the efficiency of mixtures with regard to reducing disease (Mundt, 2002). In the present study, the greater protection conferred by the resistant hybrid was due to the lesser proportion of susceptible genotype units in the mixtures. The physical protection provided by the resistant IG150 hybrid diminished the possibility of the pathogen reaching the susceptible BRS304 hybrid. This protection efficiency was less in the summer crops, as the higher temperature and humidity favor the epidemic of the disease (Frederiksen, 2000). The same environmental conditions also favored allo-infection by pathogen spores at the cultivation sites and those produced on the susceptible border plant. In the inoculated crops, the efficiency of the mixtures regarding the reduction of anthracnose was compromised by the

TABLE 4 - Phenotype diversity index and breed complexity in populations of Colletotrichum sublineolum

\begin{tabular}{lccccc}
\hline \hline Site & \multicolumn{3}{c}{ Type of index } & \multirow{2}{*}{ Number of breeds } \\
\cline { 2 - 4 } & Shannon & Simpson & Gleason & Complexity & \\
\hline Sete Lagoas & 1.744 & 0.411 & 2.693 & 4.181 & 12 \\
Indianópolis & 2.201 & 0.123 & 4.881 & 3.453 & 18 \\
Rio Verde and Paraúna & 1.944 & 0.172 & 3.102 & 3.542 & 12 \\
\hline
\end{tabular}

TABLE 5 - Components of Shannon diversity index regarding populations of Colletotrichum sublineolum

\begin{tabular}{lccc}
\hline \hline Site & \multicolumn{3}{c}{ Shannon diversity index } \\
\cline { 2 - 4 } & $\mathbf{D r}^{\mathbf{1}}$ & $\mathbf{P d}^{\mathbf{2}}$ & $\mathbf{P a}^{\mathbf{3}}$ \\
\hline Sete Lagoas & 1.744 & 1.153 & 0.525 \\
Indianópolis & 2.201 & 0.831 & 0.951 \\
Rio Verde and Paraúna & 1.944 & 0.948 & 0.886 \\
\hline
\end{tabular}

${ }^{1}$ Shannon diversity; ${ }^{2}$ loss of diversity due to deviation from ideal frequency of 0.5 of virulence and 0.5 of non-virulence; ${ }^{3}$ loss of diversity due to associations of virulence factors. 
TABLE 6 - Pearson's correlation between diversity and complexity indexes

\begin{tabular}{lcc}
\hline \hline Correlation & $\begin{array}{c}\text { Correlation } \\
\text { coefficient (r) }\end{array}$ & Significance \\
\hline Shannon x Simpson & -0.906 & $\mathrm{~ns}$ \\
Shannon x Gleason & 0.963 & $\mathrm{~ns}$ \\
Simpson x Gleason & -0.759 & $\mathrm{~ns}$ \\
Shannon x Complexity & -0.884 & $\mathrm{~ns}$ \\
Simpson x Complexity & 0.998 & $*$ \\
Gleason x Complexity & -0.726 & $\mathrm{~ns}$ \\
\hline
\end{tabular}

"significant at $1 \%$ probability (t-test); ${ }^{\text {ns non-significant at } 1 \% \text { and } 5 \%}$ probability (t-test).

increase in the inoculate potential in the experimental area. This may at least partially explain the greater protection in the plots with greater proportions of the resistant genotype, which impeded larger amounts of inoculum from reaching the susceptible material. According to Finckh et al. (2000), artificial inoculation may reduce the efficiency of mixtures regarding the control of disease in plants. Assessing sorghum plants with mixtures of the BR009B (susceptible to anthracnose), BR008 (partially resistant to anthracnose) and CMSXS210B (resistant to anthracnose), Guimarães et al. (1998) found that the plots with these mixtures reduced disease severity by as much as $78 \%$ and concluded that a greater proportion of the resistant genotype units led to a greater reduction in disease severity. This reduction in severity was attributed to a reduction in the number of pathogen allo-infections in treatments with greater proportions of resistant and partially resistant lines. Thus, the amount and type of initial pathogen inoculum in crop areas exert an influence over the efficiency of mixtures of varieties regarding the reduction in disease (Mundt, 2002).

Larger disease-progress curves were found in the summer crops than the winter crops. It should be stressed that the experimental area in Indianópolis is one of tillage sorghum. This practice contributes toward increasing the amount of initial inoculum in the area, as $C$. sublineolum can survive for up to 18 months in the absence of a host plant in the form of mycelium and conidia on croup debris on the soil surface (Costa et al., 2003). In the present study, previous crops may have increased the amount of initial inoculum in the subsequent crop, which may have contributed toward the greater intensity of the disease in summer.

The reduction in the efficiency of the mixtures may also have occurred due to an association of virulence factors in the populations analyzed. C. sublineolum is a pathogen with rare or not seen in nature sexual reproduction (Vailancourt \& Hanau, 1991). The absence of a predominant sexual recombination may influence this association (Casela et al., 2000). An unnecessary virulence gene may undergo an increase in proportion in the pathogen population due to a link to another virulence gene or aggressiveness (Brown, 1990; Van der Plank, 1982). The increase in the frequency of breeds may be explained by parasexuality, parameiosis and sexual reproduction. These are potential natural genetic recombination mechanisms that broaden variability in phytopathogens. Such mechanisms would explain the emergence of new breeds through genetic recombination in populations of C. sublineolum (Souza-Paccola et al., 2003).

Greater intensity of the disease occurred in summer than in winter in all treatments except in Treatment 3 . The most promising mixture for the reduction of disease severity was $50 \%$ of the susceptible hybrid. In summer, the disease reached its maximum and stabilized, with a tendency toward a reduction in intensity likely due to the lack of healthy leaf tissue for the pathogen, as demonstrated by the parabolic shape of the disease-progress curves (Vale et al., 2004). This shows that the increase in severity was insufficient to reach the maximal level of disease, as demonstrated by the reduction in the progress of the epidemic in the field among the mixtures and pure stands in winter.

The most efficient mixtures for the reduction of disease were not the most productive. Few studies have related production to the degree of disease infection under experimental conditions involving sorghum mixtures. In the quantification of the production of sorghum hybrid mixtures under different stress conditions, Ross (1965) found that the disease did not limit the productivity of the crop and the mixtures were not more efficient than the pure stands. It is important to stress that the productivity of the blended hybrids was not measured separately in the present study and that the small initial stand and proximity of the plants may have led to an increase in the disease and therefore affected production. The budding of the varieties occurred around 50 days after sowing and the intensification of the disease occurred around 57 days. Thus, greater disease intensity occurred after budding and therefore may have not affected the growth of the grains. These factors may have exerted an influence over the stabilization and production of the blended BRS304 variety. According to Mundt (2002), the efficiency of variety blends with regard to production is greater in crops cultivated on a commercial scale than in small experimental areas.

The resistant variety blended with the susceptible variety did not provide an increase in production and the mixtures had intermediate yields in comparison to the pure stands. Moreover, although statistically equal, the increase in the proportion of the susceptible hybrid in the mixtures was accompanied by an increase in production. Thus, if a more productive resistant hybrid were used in the mixtures, production would be optimized. Sifuentes-Barrera \& Frederiksen (1994) assessed the severity of leaf burn in sorghum mixtures using two hybrids with different degrees of resistance to E. turcicum and found that an increase in the resistant hybrid in the mixture led to an increase in the production of the susceptible hybrid.

The correlation (r) between the Simpson diversity index and complexity indicated the predominance of more 
complex breeds of $C$. sublineolum evenly distributed throughout all the sites analyzed. Valério et al. (2004) assessed 39 treatments of mixtures and pure stands of sorghum and report similar results. The authors found greater complexity in C. sublineolum breeds and a reduction in phenotype virulence diversity in the treatments with mixtures. It is possible that the greater complexity of breeds in Sete Lagoas was the result of the response of the pathogen to greater genetic diversity in the local host population. This complexity may occur due to the large number of genotypes cultivated every year in the experimental area of Embrapa Milho e Sorgo. In this case, directional selection (Van der Plank, 1982) may constitute an adaptive advantage for the pathogen. The predominance of complex breeds in the Sete Lagoas mixtures may therefore reflect a preexisting situation at the site. One may suppose that, if more genotypes from Dow Agrosciences were used for the phenotype characterization of the population in Indianópolis, breeds of greater complexity may also be identified in relation to these genotypes, which would reflect their adaptation to the resistance genes in the Dow Agrosciences genotypes.

In Rio Verde and Paraúna, more complex breeds may be well adapted because a large part of the genotypes cultivated at these sites are varieties from Embrapa Milho e Sorgo and Dow Agrosciences. It is possible that directional selection has acted in favor of more complex breeds, which are therefore well adapted to the more resistant hybrids tested. At these sites, stabilizing selection (Van der Plank, 1968) acted with lesser intensity than directional selection. Despite this greater intensity of directional selection in Indianópolis, Rio Verde and Paraúna, stabilizing selection worked toward preserving simple breeds and therefore prevented the possible extinction of such breeds in the pathogen population (Kolmer, 1991). However, genetic homogeneity per se in the fields in Rio Verde and Paraúna would not be an indicator of stabilizing selection. Resistance genes may be stacked in pyramid form in the materials cultivated in these fields. In this case, selection would act equally in favor of breed of greater complexity. This situation regarding complexity is similar to that observed in Indianópolis, where a greater amount and degree of evenness in the distribution of the breeds occurred in comparison to the site in Sete Lagoas.

The occurrence of breeds of greater complexity did not imply greater anthracnose severity in the hybrid mixtures. The same does not occur in fields and stands formed by genetically uniform varieties (Wolfe, 1985), as observed in the pure stands of the BRS304 variety and control assessed in the present study, where the increase in complex breeds in the pathogen population implied greater disease severity. In the present study, complex breeds were able to infect the resistant component of the mixture. Therefore, the reduction in the fitness of the pathogen may have been determined by a negative relation between the accumulation of virulence genes and aggressiveness. Competition between breeds may also reflect a greater or lesser proportion of complex breeds in the pathogen population. Casela et al. (2001) demonstrated the difference in competitive hability between breeds of $C$. sublineolum with different degrees of complexity.

The greater number of complex breeds detected may also be explained by genetic drift or gene flow. Complex breeds could have emerged from a small, highly virulent population to the host genotypes common to each region. This would be an adaptive advantage for the pathogen. Virulence genes in the complex breeds may become fixed in the pathogen population due to the presence of highly resistant plant varieties (Van der Plank, 1968). This may explain the high degree of complexity and low degree of diversity in the pathogen found at the sampling sites. The use of host genotypes with a high degree of resistance in each region may have directed the increase in the number of these complex breeds (Van der Plank, 1968). Consequently, complex breeds predominate over simple breeds, as seen in the results of the present study.

Complex breeds could be brought into these regions by seeds. According to Cardwel et al. (1989), $C$. sublineolum may be transported under such conditions. As there is no agricultural monitoring among sorghum cultivation regions in Brazil, the occurrence of gene flow is probable. In such cases, complex breeds of the pathogen are carried from one region to another. The transport of seeds favors a breakdown of the resistance of the plant varieties into which these breeds are introduced. Further studies are needed on the variability and composition of the population of this pathogen in infected seeds.

A reduction in the Shannon diversity index was evidenced in the present study. C. sublineolum is a fungus with rare or not easily seen sexual reproduction (Vailancourt \& Hanau, 1991). Thus, the prevalence of asexual or clonal reproduction may have influenced the association of virulence factors in the pathogen population (Casela et al., 2000; Souza-Paccola et al., 2003). This form of predominant reproduction in the pathogen favored the considerable amount of virulence associated to the particular genotypes of the differential series analyzed. Similarly, Casela et al. (2000) analyzed populations of the pathogen collected from sorghum fields in the States of Minas Gerais, São Paulo and Rio Grande do Sul (Brazil) and reported that the accentuated reductions in the Shannon diversity index in the populations studied were due to the association of virulence factors in the pathogen.

The results of the present study demonstrate that the mixture of hybrids is an efficient alternative for the management of anthracnose in sorghum. The use of sorghum mixtures increased the useful life of a hybrid with considerable agronomic and economic value (BRS304). The increase found in the complexity of $C$. sublineolum did not affect the effectiveness of these mixtures at reducing anthracnose in the short term. However, continual monitoring of these breeds and the reaction of susceptible hybrids in mixtures with resistant varieties is important. 
For such, studies should be carried out involving larger experimental areas, different growing seasons and a larger number of pathogen samples collected throughout these seasons. These types of procedures will complement the results of previous studies.

\section{ACKNOWLEDGMENTS}

The financial support of the Conselho Nacional de Pesquisa e Desenvolvimento Tecnológico - CNPq and material and structural support of Embrapa Milho e Sorgo, Brazil.

\section{REFERENCES}

Adrivon D, Vallavielle-Pope, CR (1995) Race diversity and complexity in selected populations of fungal biotrophic pathogens of cereals. Phytopathology 85:897-905.

Brow JKM (1990) Structure and evolution of a population of Erysiphe graminis f. sp. tritici. Plant Pathology 39:376-390.

Cardwel KF, Hepperly PR, Frederiksen RA (1989) Pathotypes of Colletotrichum graminicola and transmission of sorghum anthracnose. Plant Disease 73:255-257.

Casela CR, Santos FG, Ferreira AS (2000) Associação de patogenicidade e diversidade fenotípica de Colletotrichum graminicola, agente causal da antracnose em sorgo. Fitopatologia Brasileira 25:517-521.

Casela CR, Ferreira AS, Santos FG (2001) Diferences in competitive ability among races of Colletotrichum graminicola. Fitopatologia Brasileira 26:217-219.

Costa RV, Casela CR, Zambolim L, Santos FG, Vale FXR (2005) Evaluation of genetic mixtures of sorghum lines for anthracnose resistance management. Fitopatologia Brasileira 30:525-526.

Finckh MR, Gacek ES, Goyeau H, Lannou C, Merz U, Mundt CC, Munk L, Nadziak J, Newton NAC, Vallavielle-Pope C, Wolfe MS (2000) Cereal variety and species mixtures in practice. Agronomie 20:813-837.

Frederiksen RA (2000) Compendium of sorghum diseases. Saint Paul MN, USA. APS Press.

Groth JV, Roelfs AP (1987a) The concept and measurement of phenotypic diversity in Puccinia graminis on wheat. Phytopathology 77:1395-1399.

Groth JV, Roelfs AP (1987b) Analysis of virulence diversity in populations of plant pathogens. In: Wolf MS, Caten CE (Eds.) Population of plant pathogens: Their dynamics and genetics. Oxford UK. Blackwell Scientific. pp. 63-73

Guimarães FB, Casela CR, Santos FG, Ferreira AS (1998) Controle da antracnose do sorgo através da utilização de mistura de cultivares. Summa Phytopathologica 24:131-135.

Habgood H (1970) Designation of physiological races of plant pathogens. Nature 227:1268-1269.
Kolmer JA (1991) Phenotypic diversity in two populations of Puccinia recondite f.sp. tritici in Canada during 1931-1987. Phytopathology 81:311-315.

Lannou C, Mundt CC (1996) Evolution of a pathogens population in host mixtures: simple races-complex race competition. Plant Pathology 45:440-453.

Mundt CC (2002) Use of multiline cultivars and cultivar mixtures for disease management. Annual Review of Phytopathology 40:381-410.

Parlevliet JE (1993) What's durable resistance: A general outline. In: Jacobs TH, Parlevliet JE (Eds.) Durability of disease resistance. Amsterdam The Netherlands. Kluwer Academic Press. pp. 23-39.

Ramalho MAP, Ferreira DF, Oliveira AC (2005) Experimentação em genética e melhoramento de plantas. Lavras MG. Editora UFLA.

Robinson RA (1976) Plant pathosystems. Berlin Germany. Springer-Verlag.

Rosewhich UL, Pettway RE, Mcdonald BA, Duncan RR. Frederiksen RA (1998) Genetic structure and temporal dynamics of a Colletotrichum graminicola population in a sorghum disease nursery. Phytopathology 88:1087-1093.

Ross WM (1965) Yeld of grain sorghum (Shorghum vulgare Pers.) hybrids alone and in blends. Crop Science 5:593-594.

Shanner G, Finney RE (1977) The effect of nitrogen fertilization on the expression of slow mildewing resistance in knox wheat. Phytopathology 67:1051-1056.

Sifuentes-Barrera JÁ, Frederiksen RA (1994) Evaluation of sorghum hybrid mixtures for controlling sorghum leaf blight. Plant Disease 78:499-503.

Silva DD, Casela CR, Castro HA, Santos FG, Ferreira AS (2008) Diversidade populacional de Colletotrichum sublineolum em seis localidades no Brasil. Summa Phytopathologica 34:149-155.

Souza-Paccola EA, Favaro LCL, Casela CR, Paccola-Meirelles LD (2003) Genetic recombination in Colletotrichum sublineolum. Journal of Phytophatology 15:329-334.

Vaillancourt LJ, Hannau RM (1991) A method for genetic analysis of Glomerella graminicola from maize. Phytopathology 81:530534.

Valle FXR, Jesus Júnior WC, Zambolim L (Eds.) (2004) Epidemiologia aplicada ao manejo de doenças de plantas. Belo Horizonte MG. Editora Perfil.

Valério HM, Casela CR, Resende MAR, Santos FG (2004) Variability of the anthracnose fungus Colletotrichum graminicola in sorghum genotype mixtures. Fitopatologia Brasileira 29:567569.

Van der Plank JE (1968) Disease resistance in plants. New York NY, USA. Academic Press.

Van der Plank JE (1982) Host-pathogen interaction in plant disease. New York NY, USA. Academic Press.

Wolf MS (1985) The current status and prospects of multiline cultivars and variety mixtures for disease resistance. Annual Review of Phytopathology 23:251-273. 